\title{
HEAD AND NECK
}

\section{Radial vs ulnar forearm flap: a preliminary study of donor site morbidity}

\author{
Lembo d'avambraccio radiale vs lembo d'avambraccio ulnare: \\ uno studio preliminare sulla morbilità del sito donatore
}

\author{
G. BERTINO ${ }^{1}$, Y. LEPENNE¹ ${ }^{1}$ C. TINELLI², L. GIORDANO ${ }^{3}$, S. CACCIOLA ${ }^{1}$, D. DI SANTO ${ }^{3}$, A. OCCHINI ${ }^{1}$, \\ M. BENAZZO ${ }^{1}$, M. BUSSI ${ }^{3}$
}

1 Department of Otolaryngology Head Neck Surgery, University of Pavia, IRCCS Policlinico San Matteo Foundation, Pavia, Italy; ${ }^{2}$ Biometric Unit, IRCCS Policlinico S. Matteo Foundation, Pavia, Italy; ${ }^{3}$ Otolaryngology Service, Head and Neck Department, "San Raffaele" Hospital, "Vita-Salute" University, Milan, Italy

\section{SUMMARY}

The objective of this study was to compare donor site morbidity after reconstructive surgery with Ulnar Forearm Free Flap (UFFF) and Radial Forearm Free Flap (RFFF) with subjective methods. The UFFF and the RFFF were applied for reconstruction of soft tissue defects of the head and neck region in 30 patients (20 M and $10 \mathrm{~F}$; age range 28-75 years) affected by head and neck squamous cell carcinoma. The Disability of Arm, Shoulder and Hand (DASH) questionnaire was used to assess morbidity of the donor site. Analysis of the patients' DASH scores showed an overall median DASH total score of 9.17. No significant differences were observed for median values of the RFFF and UFFF groups (7.14 vs 10 respectively) or for the values in males and females (5 vs 13.3 respectively). The UFFF can be considered a valid alternative to the RFFF for reconstruction of soft tissue defects of the head and neck area; it is safe, easy to harvest and is not associated with major morbidities of the donor site as demonstrated by the DASH questionnaire.

KEY WORDS: Fasciocutaneous flap • Ulnar • Radial • Donor site morbidity •DASH questionnaire

\section{RIASSUNTO}

L'obiettivo di questo studio era di confrontare la morbilità del sito donatore dopo chirurgia ricostruttiva con il lembo libero d'avambraccio ulnare $(U F F F)$ e il lembo libero d'avambraccio radiale $(R F F F)$ con metodiche soggettive. Il UFFF e il RFFF sono stati utilizzati per la ricostruzione del difetti dei tessuti molli della testa e del collo in 30 pazienti (20 M e $10 \mathrm{~F}$; range d'età 28-75 anni), affetti da carcinoma squamocellulare della testa e del collo. Il questionario sulla disabilità per l'arto superiore DASH è stato usato per valutare la morbilità del sito donatore. L'analisi del punteggio DASH dei pazienti ha dimostrato una mediana del punteggio totale DASH di 9,17. Non sono state osservate differenze significative per $i$ valori mediani dei gruppi RFFF e UFFF (7,14 vs 10, rispettivamente) e per $i$ valori ottenuti dai maschi e dalle femmine (5 vs 13,3, rispettivamente). Il UFFF può essere considerato una valida alternativa al RFFF per la ricostruzione dei difetti dei tessuti molli del distretto testa-collo; è affidabile, semplice da trapiantare e non causa maggiori morbilità del sito donatore come dimostrato dal questionario DASH.

PAROLE CHIAVE: Lembo libero d'avambraccio $\bullet$ Ulnare $\bullet$ Radiale $・$ Morbilità del sito donatore $\bullet$ Questionario DASH

\section{Introduction}

Head and neck reconstructive surgery often requires thin and pliable tissues to achieve optimal surgical and functional outcomes. There are several reconstructive options, but forearm free flaps, since their introduction in the ' $80 \mathrm{~s}$, have been used with great success. The skin of the forearm can be harvested based on either the radial or ulnar artery; both flaps are technically easy to harvest and offer long pedicle and large calibre ${ }^{1}$. Nevertheless, while the radial forearm free flap (RFFF), proposed for the first time by Soutar et al. ${ }^{2}$, was immediately considered an easy and versatile flap, the use of the ulnar forearm free flap (UFFF), first described by Lovie in $1984^{3}$, gained less popularity than the RFFF, because of the incorrect assumption that the ulnar artery provides the dominant vascular supply for the hand ${ }^{4}$. Fortunately, the use of the UFFF in the reconstruction of head and neck region has recently increased and some authors have underlined its advantages, namely less wound-healing problems and better aesthetic outcomes of the donor site, in comparison with the RFFF, since the surface of the donor site consists of muscle bellies instead of tendons ${ }^{56}$.

However, the donor site of both flaps, especially if har- 
vested in the dominant arm, may be unsatisfactory in terms of aesthetic and functional outcomes.

The aim of this study was to evaluate donor site morbidity with subjective methods and to verify the impact of the two harvesting techniques on the daily activities of patients who underwent oncological reconstructive head and neck surgery with RFFF and UFFF, in order to evaluate which of the two flaps can be considered preferable in terms of minor morbidities.

\section{Materials and methods}

We performed a retrospective analysis of medical charts and follow-up visits of 30 patients affected by primary cancer of head and neck region who underwent surgery and reconstruction with RFFF (15 patients) or UFFF (15 patients).

All procedures were performed in two Institutions, the Department of Otolaryngology Head and Neck Surgery of the University of Pavia, IRCCS Policlinico S. Matteo Foundation, Pavia, Italy, and the Department of Otorhinolaryngology Head and Neck Surgery of the University Vita-Salute San Raffaele, San Raffaele Hospital, Milan, Italy, in the period between April 2012 and March 2016; the reconstructive procedure was carried out synchronous to ablative surgery.

Allen's test (the only mandatory test) and US Doppler were routinely performed before surgery to demonstrate adequate blood flow from the radial or ulnar artery to the hand.

\section{Surgical technique: RFFF}

The harvesting of the RFFF was conducted according to the initial description of Soutar ${ }^{2}$ (Fig. 1). The flap is designed on the forearm to include both the lateral intermuscular septum and the cephalic vein. The flap is centred on the radial artery and the course of the artery is marked on the forearm.

The upper limb is exsanguinated with a bandage and a tourniquet is applied at $250 \mathrm{mmHg}$.

The dissection is started laterally, then the circumference of the skin flap and the extension towards the cubital fossa are incised. The flap is elevated in a deep subcutaneous plane. The cephalic vein, lying deep in the subcutaneous fat, is identified, skeletonised and elevated towards its proximal course. Proceeding over the extensor and abductor tendons, the superficial branch of the radial nerve is identified, lateral to the brachioradialis tendon. Dissection is extended medially over the epitenon covering the radial nerve. Epitenon was always maintained. Medial edge of the brachioradialis muscle is retracted, underlining the

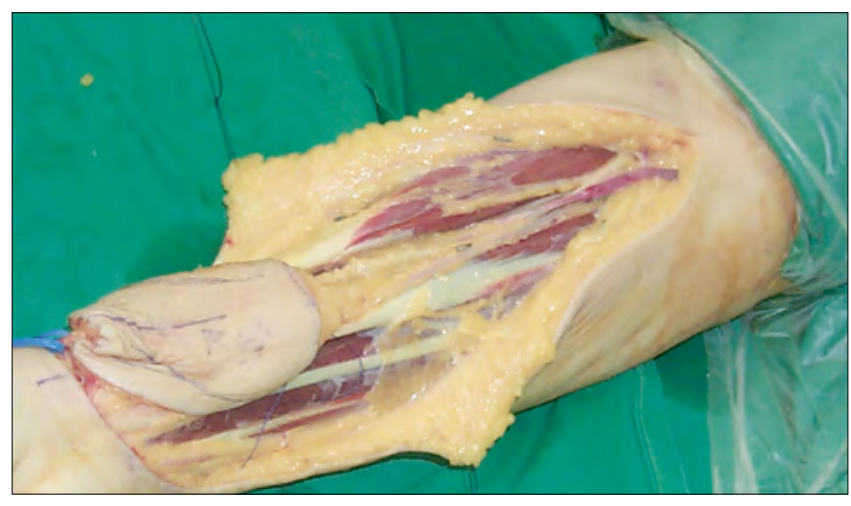

Fig. 1. Radial forearm flap harvested.

lateral intermuscular septum. Sharp dissection of the septum allows identification of the radial artery, usually running below the tendon. The fascia of the brachioradialis muscle is incised, protecting the pedicle, and the muscle is mobilised, allowing the complete visualization of the course of the radial artery. Muscle perforator branches are ligated. Next, the dissection moves to the medial side of the flap, elevating the deep fascia over the flexor muscles tendons, whose epitenon is preserved. The radial artery is identified distally to the flap, transected and ligated, together with the venae comitantes. Dissection can finally proceed from distal to proximal until enough vessel length is achieved.

Tourniquet is deflated and recipient vessels are identified and prepared for anastomotic suturing. Flap vessels are divided and the flap is transferred and inset.

RFFF was always harvested as a fasciocutaneous flap, never incorporating part of radius nor palmaris longus tendon.

Reconstruction of the donor site can be performed with a simple suture of a full thickness skin graft harvested from the groin or using the V-Y technique with a full-thickness skin graft. The skin graft is designed according to the dagger-shaped technique, as described by Giordano et al. ${ }^{7}$ The graft is elevated and defatted. Multiple slits are created on the graft to prevent fluid collection beneath it. The dagger-shaped graft is transferred and sutured to close the defect on the forearm, after undermining of the surrounding skin and suturing the proximal portion of the incision (Fig. 2). The dagger-shaped skin graft technique allows sparing of $8.3 \%$ of the skin graft, less donor site complications and better long-term aesthetic outcomes (Fig. 3).

\section{Surgical technique: UFFF}

The harvesting of the UFFF was conducted according to Lovie et al. ${ }^{3}$ and Hakim et al. ${ }^{8}$ In this case, the course 


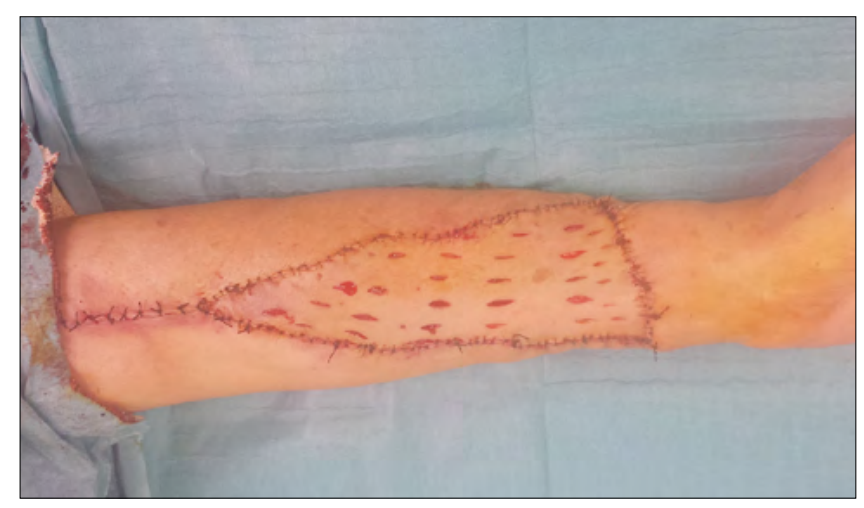

Fig. 2. Donor site reconstruction with the dagger-shaped skin graft.

of the ulnar artery on the forearm is marked drawing a line connecting the medial epicondyle of the humerus and the pisiform bone, taking care to mark the perforators at 5,7 and $12 \mathrm{~cm}$ from the pisiform bone (Fig. 4). The ulnar artery arises $1 \mathrm{~cm}$ distal to the antecubital fossa, more or less between the proximal third and middle third of the drawn line. Alternatively, it is possible to palpate the space between the belly of the flexor carpi ulnaris muscle and the superficial plexus of the fingers, at the level of the distal third of the forearm.

The cutaneous island is drawn at the middle third of the forearm, with the axis parallel to the course of the ulnar artery (Fig. 4) ${ }^{9}$.

The ulnar artery may present important anatomical variations (1-10\% of cases), as the superficial ulnar artery (SUA), so it is important to begin the flap elevation distally, re-centring the flap on the axis of the artery.

The upper limb is exsanguinated with a bandage and a tourniquet is applied at $250 \mathrm{mmHg}$.

The incision begins on the radial side at $5 \mathrm{~cm}$ from the pisiform bone, following the design of the flap, previously centred on the axis of the ulnar artery. The elevation of the flap proceeds from the radial edge to the ulnar one on a suprafascial plane, until the perforator arteries are identified. The next step is the isolation, at a subfascial level, of the best perforators for vascularisation of the cutaneous island, until their emergence from the ulnar vascular pedicle, which is dissected distal to proximal. During this manoeuvre, it is necessary to divide the vascular bundle from the ulnar nerve, taking care to retract and protect it ${ }^{10}$.

By doing so and abstaining from an immediate circumferential incision, it is possible to preliminarily identify abnormal ulnar artery courses and avoid any compromise of the vascularisation and flap survival.

Cutaneous island dissection, once the vascular pedicle has been identified, is continued at a subfascial level, beginning

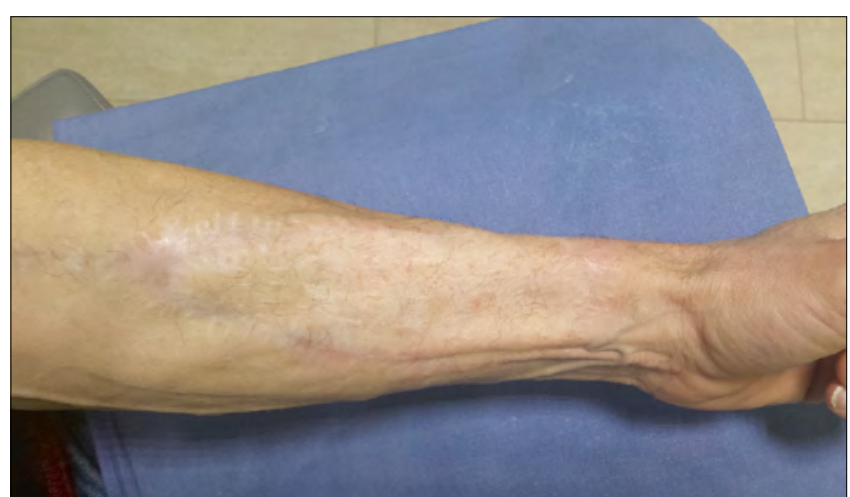

Fig. 3. Long-term aesthetic result of donor site after reconstruction with the dagger-shaped skin graft.

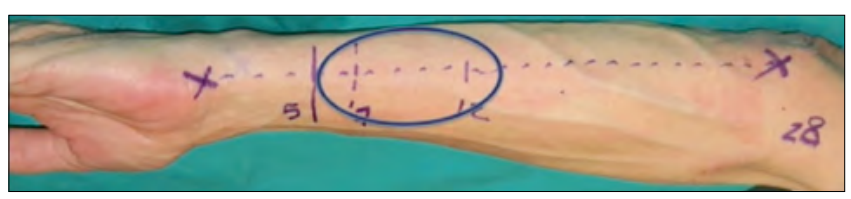

Fig. 4. Landmarks of the ulnar forearm flap and position of the cutaneous island.

from the ulnar flexor carpi. The elevation easily proceeds from below the belly of the superficial flexor digitorum muscle. It follows the vascular pedicle until the emergence of the interosseous artery is encountered and preserved. The forearm medial cutaneous nerve can be included in the harvest to give sensory innervation to the flap ${ }^{11}$.

The deep venous system of the venae comitantes has usually a good calibre for venous anastomosis, and sometimes it is possible that the two satellites veins join to form a single vein ${ }^{11}$.

Therefore, the basilic vein is dissected as well and included into the flap, so that another way of venous drainage of the flap is assured (Fig. 5).

Once the entire flap is elevated, the vascular pedicle is dissected, but not sectioned, until the surgical team is ready for the reconstruction (Fig. 5).

At this point, the vascular pedicle is tied up and dissected before the emergency of the interosseous artery, preserving the deep vascularisation of the forearm.

The ulnar artery is anastomosed usually with a branch of the external carotid artery (lingual, facial or superior thyroid arteries). The choice of the branch depends on a good size match between the ulnar artery and neck vessels and on the length of the vascular pedicle. For venous anastomosis, the basilic vein and/or one or both of the ulnar comitantes veins are used. The choice depends on the calibre of the veins and on the predominance of the venous drainage 


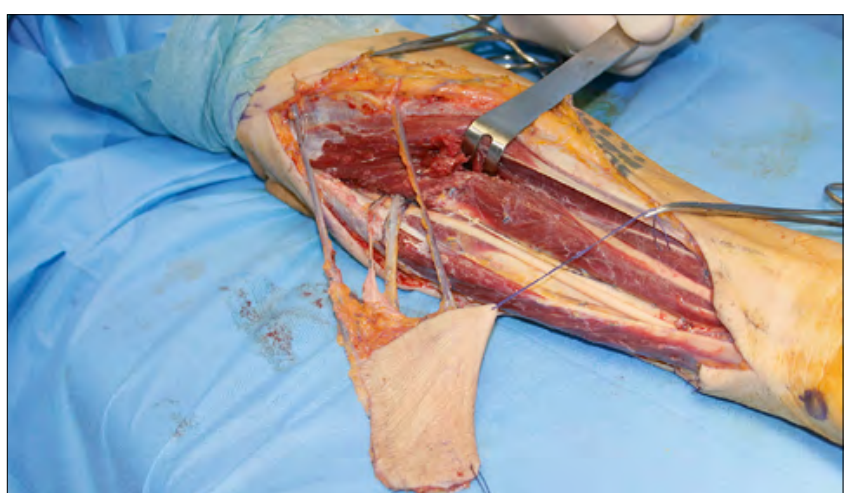

Fig. 5. Ulnar forearm flap harvested.

of the flap (comitantes veins vs basilic vein). The most frequently used veins for venous anastomosis are the thyrolingual-facial trunk or the internal or external jugular vein. The second venous anastomosis is performed if the venous drainage of the first venous anastomosis is insufficient.

All the dissections were performed on the non-dominant arm and the skin defect was closed with a full-thickness skin graft harvested from the patient's groin.

\section{Follow-up}

In order to evaluate donor site outcomes, all patients were submitted, during the first follow-up visit, to the Italian version of the "Disabilities of Arm, Shoulder and Hand Questionnaire" (DASH) ${ }^{12}$.

The DASH score ${ }^{11}$ is a patient subjective score with 30 responses about symptoms and functional status during routine daily activities producing a score between 0 and 100 points. The questionnaire is divided into the following sections: symptoms, sport, music and work. The first section is composed of 30 items and evaluates symptoms and functional status, the second and third parts are two optional modules of 4 questions for sport and music and 4 questions for work. The parts regarding sport, music and work were not taken into consideration because of the low numbers of answers (10\% of patients).

Each item is scored with a 5-point scale ranging from $1=$ no difficulty from $5=$ unable. The results are summed and transformed into the DASH score in the following way:

(absolute score -30$) / 1.2=$ DASH total score

The DASH total score, as above calculated, ranges from 0 (no disability) to 100 (severe disability).

\section{Statistical analysis}

Quantitative variables (age, follow-up time, DASH scores) were not normally distributed (Shapiro-Wilk test) and so the results were expressed as median and interquartile range (IQR; $25^{\text {th }}-75^{\text {th }}$ percentile). The comparisons between the two groups were evaluated with Wilcoxon ranksum test. Qualitative variables were summarised as counts and percentages.

In order to evaluate differences between the ability to practice daily activities and some symptoms of the arm, we separately analysed the first 23 questions regarding the ability to do certain activities and if and how the arm and hand problems interfered with normal social activities (DASH 1-23 score), from the 5 questions (DASH 24-28 score) regarding pain, tingling, weakness and stiffness of the arm and hand, and we then analysed the answers in percentages.

A p $<0.05$ was considered statistically significant. All tests were two-sided. The data analysis was performed with the STATA statistical package (release 14.0, 2015, Stata Corporation, College Station, Texas, USA).

\section{Results}

\section{Patient demography}

The patients' demography is described in Table I.

One third of patients had an early stage cancer (I-II) and the oral cavity was the most represented site of the primary disease $(63.3 \%)$. The two reconstructive options (RFFF and UFFF) were equally distributed. A selective neck dissection, homolateral to the donor site, was performed in 12 patients.

We observed no complications at the donor site in either group, with complete integration of the skin graft and no exposure of tendons in all patients. The mean healing time of the donor site was comparable in both groups: 29.7 days for UFFF and 31.1 for RFFF.

\section{DASH score}

The DASH score data are summarised in Tables II and III. No significant difference was observed, except for the DASH 24-28 between patients undergoing neck dissection and those who did not.

The values were 17.5 ( $\min .0$ - $\max .40$ ) and 3.76 (min. 0 - max. 65). These differences were near the level of statistical significance $(\mathrm{p}=0.08)$ (Table III).

\section{Discussion}

The RFFF represents a widely known reconstructive option in head and neck oncological surgery. It is thin and pliable, making it ideal for the reconstruction of head and neck defects. While the use of the RFFF is well estab- 
Table I. Patient demography.

\begin{tabular}{|c|c|c|c|}
\hline & Total & $\operatorname{RFFF}(\mathrm{N}=15)$ & UFFF $(\mathrm{N}=15)$ \\
\hline $\begin{array}{l}\text { Sex } \\
\text { male } \\
\text { female }\end{array}$ & $\begin{array}{l}20(66.7 \%) \\
10(33.3 \%)\end{array}$ & $\begin{array}{l}9(30 \%) \\
6(20 \%)\end{array}$ & $\begin{array}{c}11(36.7 \%) \\
4(13.3 \%)\end{array}$ \\
\hline $\begin{array}{l}\text { Age at the day of surgery } \\
\text { median (IQR) } \\
\text { range }\end{array}$ & $\begin{array}{c}58.3(50.4-64.8) \\
28.6-75.4\end{array}$ & $\begin{array}{c}57.8(50.2-67.5) \\
28.6-75.4\end{array}$ & $\begin{array}{c}58.8(51.1-63.8) \\
30.3-74.4\end{array}$ \\
\hline $\begin{array}{l}\text { Stage } \\
\text { II } \\
\text { III } \\
\text { IV }\end{array}$ & $\begin{array}{l}3(10 \%) \\
7(23.3 \%) \\
5(16.7 \%) \\
15(50 \%)\end{array}$ & $\begin{array}{c}- \\
5(16.6 \%) \\
3(10 \%) \\
7(23.2 \%)\end{array}$ & $\begin{array}{l}3(10 \%) \\
2(6.7 \%) \\
2(6.7 \%) \\
8(26.8 \%)\end{array}$ \\
\hline $\begin{array}{l}\text { Primary tumour site } \\
\text { oral cavity } \\
\text { oropharynx } \\
\text { hypopharynx } \\
\text { oral cavity/oropharynx } \\
\text { hypopharynx/cervical oesophagus }\end{array}$ & $\begin{array}{l}19(63.4 \%) \\
5(16.7 \%) \\
4(13.3 \%) \\
1(3.3 \%) \\
1(3.3 \%)\end{array}$ & $\begin{array}{c}10(33.7 \%) \\
2(6.7 \%) \\
3(10 \%) \\
- \\
-\end{array}$ & $\begin{array}{c}9(29.7 \%) \\
3(10 \%) \\
1(3.3 \%) \\
1(3.3 \%) \\
1(3.3 \%)\end{array}$ \\
\hline $\begin{array}{l}\text { Demolitive surgery } \\
\text { circular pharyngolaryngectomy } \\
\text { partial buccopharyngectomy } \\
\text { hemiglossectomy } \\
\text { simple exeresis } \\
\text { partial pharyngectomy } \\
\text { pelvectomy } \\
\text { pelviglossectomy }\end{array}$ & $\begin{array}{c}3(9.9 \%) \\
2(6.6 \%) \\
17(57.1 \%) \\
2(6.6 \%) \\
2(6.6 \%) \\
2(6.6 \%) \\
2(6.6 \%)\end{array}$ & $\begin{array}{c}1(3.3 \%) \\
1(3.3 \%) \\
9(30.2 \%) \\
1(3.3 \%) \\
2(6.6 \%) \\
1(3.3 \%) \\
-\end{array}$ & $\begin{array}{c}2(6.6 \%) \\
1(3.3 \%) \\
8(26.9 \%) \\
1(3.3 \%) \\
- \\
1(3.3 \%) \\
2(6.6 \%)\end{array}$ \\
\hline $\begin{array}{l}\text { Head and neck site } \\
\text { Tongue + Floor of the mouth } \\
\text { Oropharynx } \\
\text { Hypopharynx }\end{array}$ & $\begin{array}{c}19(63.3 \%) \\
6(20 \%) \\
5(16.7 \%)\end{array}$ & $\begin{array}{c}10(33.3 \%) \\
2(6.7 \%) \\
3(10.0 \%)\end{array}$ & $\begin{array}{l}9(30.0 \%) \\
4(13.3 \%) \\
2(6.7 \%)\end{array}$ \\
\hline $\begin{array}{l}\text { Neck dissection ipsilateral to the donor site } \\
\text { not performed } \\
\text { selective }\end{array}$ & $\begin{array}{l}18(60 \%) \\
12(40 \%)\end{array}$ & $\begin{array}{c}11(36.7 \%) \\
4(13.3 \%)\end{array}$ & $\begin{array}{l}7(23.3 \%) \\
8(26.7 \%)\end{array}$ \\
\hline
\end{tabular}

lished in clinical practice, the UFFF is used occasionally, even though in recent years there has been an increase of its use as a reconstructive option, essentially due to the erroneous assumption that the ulnar artery provides the dominant vascular supply for the hand ${ }^{4}$ and operator-dependent limits, as superficial knowledge of the anatomy of the forearm deep muscles and the risk to damage the ulnar nerve, which lies next the ulnar vessels and it is vascularised by the ulnar artery branches ${ }^{11}$. The surgical technique for UFFF harvesting, however, does not present greater difficulties than that of the radial flap, requiring about the same surgical time.

The artery and the venae comitantes of the ulnar pedicle are more reliable because they have calibres that are similar to those of the branches of the external carotid artery and internal jugular vein respectively ${ }^{9}$. This is not always

Table II. Median (IQR) DASH score for the whole group of patients and for the two types of flaps.

\begin{tabular}{|c|c|c|c|c|c|c|c|c|c|}
\hline & \multicolumn{3}{|c|}{ OVERALL $(\mathrm{N}=30)$} & \multicolumn{3}{|c|}{ RFFF (N = 15) } & \multicolumn{3}{|c|}{ UFFF ( $N=15)$} \\
\hline & Total & $F(N=10)$ & $M(N=20)$ & Total & $F(N=6)$ & $M(N=9)$ & Total & $F(N=4)$ & $M(N=11)$ \\
\hline DASH total & $\begin{array}{c}9.17 \\
(0.9-28.3)\end{array}$ & $\begin{array}{c}13.3 \\
(10-31.7)\end{array}$ & $\begin{array}{c}5 \\
(0.9-27.9)\end{array}$ & $\begin{array}{c}7.14 \\
(0-28.3)\end{array}$ & $\begin{array}{c}12.7 \\
(0.9-31.7)\end{array}$ & $\begin{array}{c}3.33 \\
(0-9.8)\end{array}$ & $\begin{array}{c}10 \\
(3.3-32.8)\end{array}$ & $\begin{array}{c}13.3 \\
(11.3-23.5)\end{array}$ & $\begin{array}{c}5.83 \\
(1.7-47.4)\end{array}$ \\
\hline DASH 1-23 & $\begin{array}{c}6.67 \\
(0-28.3)\end{array}$ & $\begin{array}{c}12.2 \\
(6.8-33)\end{array}$ & $\begin{array}{c}5.1 \\
(0-23.9)\end{array}$ & $\begin{array}{c}4.76 \\
(0-28.3)\end{array}$ & $\begin{array}{c}9.67 \\
(1.1-35.9)\end{array}$ & $\begin{array}{c}3.26 \\
(0-5.4)\end{array}$ & $\begin{array}{c}9.78 \\
(0-33)\end{array}$ & $\begin{array}{c}12.5 \\
(10.2-23)\end{array}$ & $\begin{array}{c}6.52 \\
(0-48.9)\end{array}$ \\
\hline DASH 24-28 & $\begin{array}{c}10 \\
(0-25)\end{array}$ & $\begin{array}{c}8.76 \\
(0-20)\end{array}$ & $\begin{array}{c}10 \\
(2.5-27.5)\end{array}$ & $\begin{array}{c}5 \\
(0-20)\end{array}$ & $\begin{array}{c}8.76 \\
(0-20)\end{array}$ & $\begin{array}{c}5 \\
(0-15) \\
\end{array}$ & $\begin{array}{c}10 \\
(5-30)\end{array}$ & $\begin{array}{c}15.4 \\
(0.4-30)\end{array}$ & $\begin{array}{c}10 \\
(5-40)\end{array}$ \\
\hline
\end{tabular}


Table III. Median (IQR) DASH score in patients submitted or not to neck dissection ipsilateral to the donor site.

\begin{tabular}{lcc} 
& $\begin{array}{c}\text { No neck dissection } \\
(\mathbf{N}=18)\end{array}$ & $\begin{array}{c}\text { Neck dissection } \\
(\mathbf{N}=12)\end{array}$ \\
DASH total & 7.5 & 11.7 \\
& $(0.8-15)$ & $(2.5-32.2)$ \\
DASH 1-23 & 5.98 & 10.9 \\
& $(0-13)$ & $(0-34.4)$ \\
DASH 24-28 & $3.76^{*}$ & $17.5^{*}$ \\
& $(0-20)$ & $(10-27.5)$ \\
\hline
\end{tabular}

$p=0.08$

true for the pedicle of the radial forearm flap: in fact, the diameter of the artery and, in particular of the venae comitantes, are usually smaller than the neck vessels, making anastomoses more difficult.

Despite its frequent use, the radial flap presents, compared to the ulnar one, some disadvantages: the cutaneous island site is more distal and involves exposure of flexor muscle tendons, while the UFFF involves exposure of muscles bellies, which constitutes a better bed for skin graft engraftment; the donor site is more visible, which leads to a lower cosmetic outcome (less accepted by women), and the skin is more hairy, representing an important disadvantage for reconstruction of the oral cavity and pharynx. Nevertheless, a possible advantage of RFFF is the possibility to prepare a full-thickness graft in the same donor area site: this graft has a similar coloured texture of the skin of the donor site and can be done without an additional surgical field, as described by Squadrelli-Saraceno et al. ${ }^{13}$ and Giordano et al. ${ }^{7}$. The closure technique is comfortable, useful and provides a satisfactory cosmetic result. Instead, the UFFF donor site is closed with a fullthickness graft of a distant site.

The forearm fasciocutaneous flaps have, for both types, a certain degree of donor site morbidity.

The pre-operative assessment of the vascularisation of the hand with Allen's test is mandatory to reduce the incidence of the most feared complication for this surgery: hand ischaemia. In case of subjective anomalies, an objective Allen's test should be performed, since it offers greater specificity and sensibility ${ }^{14}$. Other complications include wound dehiscence, partial or total skin necrosis and sensory and motor hand disorders, such as cold intolerance ${ }^{1}$.

In the literature, there are several studies that have evaluated donor site morbidity after RFFF or UFFF harvesting with objective or subjective methods, e.g. Sieg et al. ${ }^{6}$ and Hekner et al. ${ }^{8}$. These authors have shown, evaluating the modality of donor site healing with pressure or heat measurements, that the morbidity is significantly lower for the ulnar flap than the radial one, because the skin graft used to cover the donor site lies on the muscle bellies and not on the tendons, like in the RFFF, resulting in a lower risk of retracting and ankylosing scars. Nevertheless, the subjective evaluation of donor site morbidity by patients showed no significant differences between the two groups, and the most widely used method to assess it is the DASH questionnaire. In the literature, it has been reported that the median values of DASH for ulnar flaps range from 3.4 to $13.3^{1015}$. In our study, we observed similar values for both the UFFF (10) and the RFFF (7.4); this is maybe dependent on the closure technique with a transposition flap or with a full thickness skin graft, which gives a more effective protection of the tendons in RFFF. Nevertheless, these results must be considered somewhat preliminary due to the small size of our cohort.

We observed no complications in terms of donor site healing in either study group, and thus we have no data about the possible effects of complications on the DASH score. The analysis of scores for the first 23 questions on evaluation of the ability to perform daily activities and in the 24-28 questions about the presence of pain, numbness, stiffness or weakness did not reveal significant differences between RFFF and UFFF patients, confirming that both groups showed no severe disability or sensory-motor deficits. This result is probably due to the choice of the nondominant arm for surgery and the use of a full-thickness skin graft to close the skin defect, which reduces the possibility of retracting scars between the graft and muscles or tendons.

Evaluation of DASH scores based on sex showed lower median scores in male patients than those obtained in female patients, although the difference was not statistically significant. This is probably due to the fact that, even if in women aesthetic damage is an important factor, the scar is not considered particularly disfiguring to the forearm, although this aspect should be confirmed with additional studies with larger case series.

Neck dissection-related shoulder disability could possibly negatively influence the DASH scores, giving additional morbidities to those of the flap harvest. For this reason, we checked the presence of possible significantly different scores between the patients in whom neck dissection was performed on the ipsilateral site of the flap harvest and the ones in whom it was not. The comparison did not reveal significant differences, with the exception of the DASH 24-28 score, regarding pain, tingling, weakness, and stiffness of the arm, in which the difference was close to the level of statistical significance.

To the best of our knowledge, there are no papers in the literature that have evaluated this aspect; we believe that it 
should be taken into consideration in the evaluation of the donor site morbidity in order to differentiate between the effects of the flap harvest and those of the neck dissection. Despite this possible bias, our results allowed us to consider the DASH questionnaire an appropriate and reliable method to assess donor site morbidity after dissection of a radial or ulnar forearm flap.

\section{Conclusions}

RFFF and UFFF are suitable choices for oncologic reconstruction of head and neck defects. Both have a long vascular pedicle of appropriate size; they are thin and pliable and guarantee good aesthetic and functional results.

Major advantages of the ulnar flap over the radial flap seem to be the better calibre of the ulnar artery and the venae comitantes, resulting in a better correspondence with the diameter of the neck vessels; more hairless skin, ideal quality for intraoral and pharyngeal reconstructions, and a less exposed donor site.

Nevertheless, additional studies with larger case series are necessary to compare long-term donor site morbidity between these two reconstructive options, and the DASH questionnaire may be considered a valid method of evaluation.

\section{Conflict of interest statement}

None declared.

\section{References}

1 Orlik JR, Horwich P, Bartlett C, et al. Long-term functional donor site morbidity of the free radial forearm flap in head and neck cancer survivors. J Otolaryngol Head Neck Surg 2014;43:1-7. https:// doi.org/10.1186/1916-0216-43-1.

2 Soutar DS, Scheker LR, Tanner NS, et al. The radial forearm flap: a versatile method for intra-oral reconstruction. Br J Plast Surg 1983;36:1-8. https://doi.org/10.1016/0007-1226(83)90002-4.

3 Lovie MJ, Duncan GM, Glasson DW. The ulnar artery forearm free flap. Br J Plast Surg 1984;37:486-92. https://doi.org/10.1016/00071226(84)90136-x.

4 Haerle M, Hafner HM, Dietz K, et al. Vascular dominance in the forearm. Plast Reconstr Surg 2003;111:1891-8. https://doi. org/10.1097/01.PRS.0000057529.76413.D7.

5 Hekner DD, Abbink JH, Van Es RJ, et al. Donor-site morbidity of the radial forearm free flap versus the ulnar forearm free flap. Plast Reconstr Surg 2013;132:387-93. https://doi.org/10.1097/ PRS.0b013e318295896c.

6 Sieg P, Bierwolf S. Ulnar versus radial forearm flap in head and neck reconstruction: an experimental and clinical study. Head Neck 2001;23:967-71. https://doi.org/10.1002/hed.1140.

7 Giordano L, Bondi S, Ferrario F, et al. Radial forearm free flap surgery: a modified skin-closure technique improving donor-site aesthetic appearance. Acta Otorhinolaryngol Ital 2012;32:158-63.

8 Hakim SG, Trenkle T, Sieg P, et al. Ulnar artery-based free forearm flap: review of specific anatomic features in 322 cases and related literature. Head Neck 2014;36:1224-9. https://doi.org/10.1002/ hed.23594.

9 Yu P, Chang EI, Selber JC, et al. Perforator patterns of the ulnar artery perforator flap. Plast Reconstr Surg 2012;129:213-20. https:// doi.org/10.1097/PRS.0b013e3182362a9c.

10 Brown EN, Chaudhry A, Mithani SK, et al. Long-term vascular, motor and sensory donor site outcomes after ulnar forearm flap harvest. J Reconst Microsurg 2014;30:115-20. https://doi. org/10.1055/s-0033-1357271.

11 Wax MK, Rosenthal EL, Winslow CP, et al. The ulnar fasciocutaneous free flap in head and neck reconstruction. Laryngoscope 2002;112:2155-60. https://doi.org/10.1097/00005537-20021200000005.

12 Hudak P, Amadio P, Bombardier C. Development of an upper extremity outcome measure: the DASH (disabilities of the arm, shoulder and hand) [Corrected]. The Upper Extremity Collaborative Group (UECG). Am J Ind Med 1996;29:602-8. Erratum in: Am J Ind Med 1996;30:372. https://doi.org/10.1002/(SICI)10970274(199606)29:6<602::AID-AJIM4>3.0.CO;2-L.

13 Squadrelli-Saraceno M, Compan A, Bimbi G, et al. Autonomous Reparative Unit (ARU): a new concept of repairing free flap donor site with local full-thickness skin graft. Acta Otorhinolaryngol Ital 2010;30:40-6.

14 Wood JW, Broussard KC, Burkey B. Preoperative testing for radial forearm free flaps to reduce donor site morbidity. JAMA Otolaryngol Head Neck Surg 2013;139:183-6. https://doi.org/10.1001/ jamaoto.2013.1357.

15 Sieg P, Dericioglu M, Hansmann C, et al. Long-term functional donor site morbidity after ulnar forearm flap harvest. Head Neck 2012;34:1312-6. https://doi.org/10.1002/hed.21918.

Received: February 7, 2018 - Accepted: May 2, 2018

How to cite this article: Bertino G, Lepenne Y, Tinelli C, et al. Radial vs ulnar forearm flap: a preliminary study of donor site morbidity. Acta Otorhinolaryngol Ital 2019;39:322-328; https://doi.org/10.14639/0392-100X-2102

Address for correspondence: Yuri Lepenne, University of Pavia, Department of Otolaryngology Head Neck Surgery, IRCCS Policlinico San Matteo Foundation, p.le Golgi 2, 27100 Pavia, Italy. E-mail: yuri.lepenne.89@ gmail.com

This is an open access article distributed in accordance with the Creative Commons Attribution Non Commercial (CC BY-NC 4.0) license, which permits others to distribute, remix, adapt, build upon this work non-commercially, and license their derivative works on different terms, provided the original work is properly cited, appropriate credit is given, any changes made indicated, and the use is non-commercial. See: http://creativecommons.org/licenses/by-nc/4.0/. 